\title{
PRECIPITAÇÃO PLUVIAL DE DIAMANTINO-MT EM ANOS DE OCORRÊNCIA DE EL NIÑO, LA NIÑA E NEUTROS
}

\author{
HENRIQUE DA CRUZ RAMOS ${ }^{1}$, RIVANILDO DALLACORT ${ }^{1}$, ADALBERTO SANTI ${ }^{1}$, SANTINO \\ SEABRA JUNIOR ${ }^{2}$, TADEU DE MIRANDA QUEIROZ ${ }^{3}$
}

${ }^{1}$ Universidade do Estado de Mato Grosso (UNEMT), Departamento de Agronomia, Tangará da Serra, MT, Brasil

${ }^{2}$ UNEMT, Departamento de Agronomia, Nova Mutum, MT, Brasil

${ }^{3}$ UNEMT, Departamento de Engenharia de Produção Agroindustrial, Barra do Bugres, MT, Brasil

henriquecruzr@gmail.com,rdallacort@unemat.br, adalbertosanti@unemat.br, santinoseabra@hotmail.com, tdmqueiroz@yahoo.com.br

Recebido Abril de 2012 - Aceito Fevereiro de 2014

\begin{abstract}
RESUMO
O objetivo deste trabalho foi caracterizar a variação da precipitação pluvial anual, mensal e decendial, em anos normais e com a ocorrência do fenômeno ENOS no município de Diamantino-MT. Foram utilizados os dados do período de 1968 a 2003, cedidos pelo Instituto Nacional de Meteorologia. A determinação da precipitação provável anual foi através da distribuição gama e para aferir se os dados se adequavam ao modelo utilizado, o teste de aderência de Kolmogorov-Smirnov foi aplicado. De modo geral as médias mensais dos anos caracterizaram duas fases distintas no comportamento da pluviosidade da região, uma chuvosa (outubro a abril) e outra seca (maio a setembro). A ocorrência do ENOS causa uma redução na média anual precipitada. A fase La Niña do ENOS é que mais altera a distribuição temporal das chuvas em relação aos anos neutros, apresentando os maiores valores precipitados do quarto ao sétimo decêndio do ano. Os anos de El Niño apresentaram as maiores intensidades de precipitação no período compreendido entre os meses de janeiro a março. Os anos neutros apresentaram as maiores precipitações $(1.862,7 \mathrm{~mm})$ seguidos por anos de El Niño $(1.729,2 \mathrm{~mm})$ e anos de La Niña $(1.712,5 \mathrm{~mm})$.
\end{abstract}

Palavras-chave: clima, chuva, metereologia agrícola.

\begin{abstract}
PLUVIAL PRECIPITATION IN EL NIÑO, LA NIÑA AND NEUTRAL YEARS IN DIAMANTINO, MT

The aim of this work was to describe the annual, monthly and ten-day pluvial precipitation variation during El Niño Southern Oscillation and neutral years, in the city of Diamantino, MT. Data from 1968 to 2003, provided by the Instituto Nacional de Metereologia, was used. To determine the most probable annual rainfall the gamma distribution was used. To check for the data fitness to the used model, the Kolmogorov-Smirnov test was applied. In general, monthly averages have described two distinct phases for the rainfall in the region, a wet season (October to April) and a dry season (May to September). The occurrence of El Niño Southern Oscillation causes a reduction on the annual average rainfall. The rainfall distribution is altered more intensely during the La Niña phase compared to neutral years, showing the highest precipitation during the fourth to the seventh ten-days periods of the year. The El Niño years present higher precipitation during January to March. The neutral years showed the highest precipitation $(1862.7 \mathrm{~mm})$ followed by El Niño years $(1729.2 \mathrm{~mm})$ and La Niña years $(1712.5 \mathrm{~mm})$.
\end{abstract}

Keywords: climate, rainfall, agricultural meteorology. 


\section{INTRODUÇÃO}

Nos últimos 30 anos o estado de Mato Grosso tornou-se uma das principais regiões agrícolas do Brasil. No início do século 21 este estado assumiu a posição de maior produtor de grãos do país. A região da Chapada dos Parecis, onde está inserido o município de Diamantino, ocupa uma posição de destaque na produção nacional de cana-de-açúcar, soja e sorgo (Dubreuil et al., 2005).

A quantidade de precipitação pluvial e a forma como essa distribui-se são determinantes no tipo de vegetação presente em determinada região e atividade agrícola que é realizada (Pereira et al., 2002). No Brasil, grande parte dos cultivos é realizada em sequeiro. Neste modelo as culturas dependem exclusivamente da precipitação pluvial para o seu desenvolvimento (Sousa, 1998).

Os efeitos do fenômeno El Niño Oscilação Sul (ENOS) podem ser sentidos em boa parte do planeta, sendo considerado assim um fenômeno de escala global. Sua ocorrência está ligada ao forte acoplamento oceano-atmosfera que ocorre sobre a região equatorial do oceano Pacífico (Podestá et al., 1999). Os efeitos do ENOS começam a ser sentidos no segundo semestre de um ano e estende-se normalmente até a primeira metade de outro ano, sendo composto por duas fases distintas a El Niño ou fase quente e a La Niña ou fase fria (Berlato et al. 2005).

Segundo Alves et al. (1997) o ENOS, exerce grande influência sobre clima do Brasil, sendo a precipitação um dos elementos do clima mais modificados pela ocorrência deste fênomeno, aumentando ou diminuindo a altura pluviométrica.

A fase El Niño é causada por um aquecimento anormal das águas do oceano Pacífico que geralmente resulta em um aumento na precipitação nos anos em que ele ocorre. Já a fase La Niña é resultante de um resfriamento nas águas do oceano Pacífico gerando um efeito contrário ao El Niño, ou seja uma redução na precipitação média dos anos em questão (Grimm et al. 2000). As duas fases deste fenômeno afetam o desempenho produtivo das espécies agrícolas de forma positiva e negativa. Fato este que foi observado por Berlato et al. (2005) no estado do Rio Grande do Sul, em que, nos anos de ocorrência do El Niño há um aumento no rendimento do milho e uma queda na produção nos anos em que ocorre La Niña. Para a cultura do arroz irrigado no Rio Grande do Sul, Carmona e Berlato (2002) verificaram que os episódios de El Niño diminuem o rendimento desta cultura, pois há uma menor disponibilidade de insolação de outubro a fevereiro, e para La Niña a cultura é favorecida graças ao fato de ocorrerem altos níveis de insolação no mesmo período. Cunha (1999) observou que na região Sul do país anos de El Niño, em geral, as culturas de verão, como soja e milho, são beneficiadas, já nos anos de La Niña a cultura de trigo é favorecida.

Este trabalho objetivou caracterizar a variabilidade da precipitação pluvial anual, mensal e decendial, de 1961 a 2003 em anos normais e com a ocorrência do fenômeno ENOS no município de Diamantino-MT.

\section{MATERIAL E MÉTODOS}

O Município de Diamantino-MT (Figura 1) está localizado na região da Chapada do Parecis e tem como principal atividade econômica a agricultura desenvolvida principalmente em regime de sequeiro. Destacando-se nacionalmente na produção de soja, sendo apontado como um dos maiores produtores deste grão. O clima da região, segundo a classificação de KÖPPEN, é tropical úmido megatérmico (Aw), com temperaturas elevadas, chuva no verão e seca no inverno. A média da temperatura ao longo do ano é de $24,4^{\circ} \mathrm{C}$

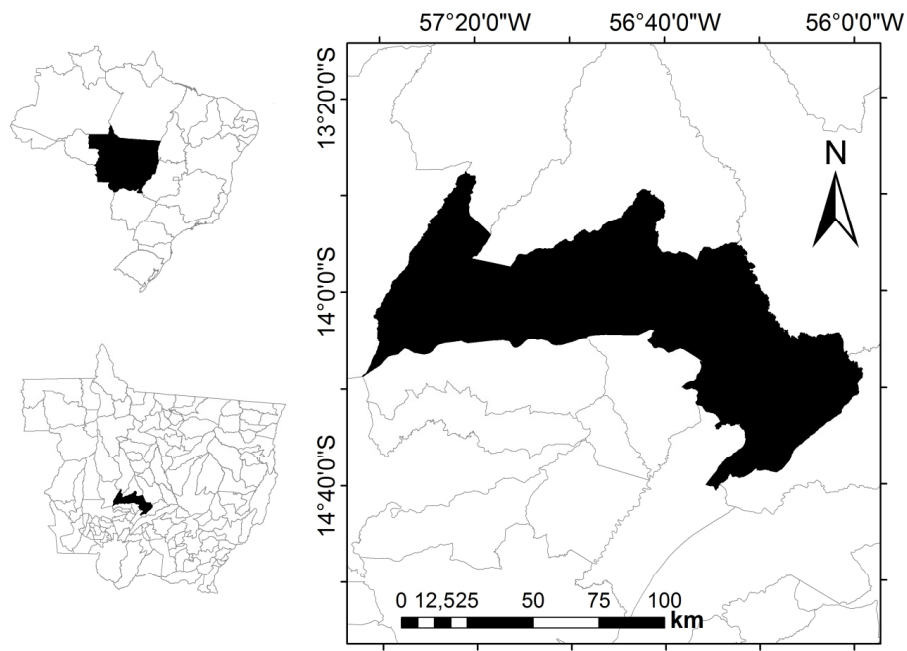

Figura 1: Localização espacial e limites políticos do município de Diamantino - MT. 
Tabela 1: Relação dos anos utilizados no trabalho.

\begin{tabular}{|c|c|}
\hline Evento ocorrido & Anos \\
\hline El Niño & $\begin{array}{l}1963-1964,1965-1966 *, 1969-1970,1972-1973,1976-1977,1982-1983, \\
1986-1987,1987-1988,1991-1992 *, 1992-1993 *, 1993-1994 *, 1994- \\
1995 *, 1997-1998 *, 2002-2003 .\end{array}$ \\
\hline La Niña & $\begin{array}{l}1964-1965,1967-1968 *, 1970-1971,1971-1972,1973-1974,1974-1975, \\
1975-1976,1988-1989,1995-1996 *, 1998-1999,1999-2000 .\end{array}$ \\
\hline Anos Neutros & $1961,1962,1978,1979 *, 1980,1981,1984,1990^{*}$. \\
\hline
\end{tabular}

*Anos não utilizados devido a falhas nas séries históricas.

Os dados para realização do presente trabalho foram cedidos pelo Instituto Nacional de Meteorologia (INMET), o qual possui uma estação meteorológica no município de Diamantino, localizada nas coordenadas $14^{\circ} 24^{\prime}$ S $56^{\circ} 27^{\prime}$ W e altitude de $286,3 \mathrm{~m}$. Foram utilizados dados diários de precipitação pluviométrica, no período compreendido entre os anos de 1961 a 2003. Para o preenchimento de falhas foi utilizado o software CLIMA (Faria et al., 2003) desenvolvido pelo Instituto Agronômico do Paraná (IAPAR).

A precipitação não foi análisada seguindo o calendário normal do ano civil, pois este fênomeno ocorre de julho de um ano a junho do próximo, deste modo os dados foram tabulados de modo que se isolasse o período de interferência do ENSO. Os anos com ocorrência do fenômeno ENOS no período de 1961 a 1992 foram caracterizados por Podestá et al. (1999), os fenômenos ocorridos após o ano de 1992 e até o ano de 2003 foram descritos por Berlato et al. (2005), seguindo a metodologia de Podestá et al. (1999). Foram considerados anos neutros onde não houve a influência do fenômeno (Tabela 1). Porém, não foram utilizados todos os anos pertencentes ao intervalo de 1961 a 2004, isto devido a falhas ocorridas na coleta de dados o que inviabilizou o uso dos mesmos.

Foram quantificados os dias secos e chuvosos, considerando dias secos os dias que apresentam precipitação inferior a $5 \mathrm{~mm}$ e dia chuvoso dias quando a precipitação excede o valor de $5,1 \mathrm{~mm}$, pois considerou-se dia chuvoso o dia que há excedente hídrico considerando-se que em média ocorre uma evapotranspiração de $5 \mathrm{~mm}$ por dia, conforme utilizado por Sans et al. (2001).

Foi feita a frequência média da precipitação diária, agrupando as ocorrências nos seguintes intervalos: 5,1 a 10 $\mathrm{mm}, 10,1$ a $15 \mathrm{~mm}, 15,1$ a 20, 20,1 a 30, 30,1 a $40 \mathrm{~mm}, 40,1$ a $50 \mathrm{~mm}$ e precipitações maiores que $50,1 \mathrm{~mm}$ como o tuilizado por Dallacort et al (2011).

A determinação e análise da probabilidade pluviométrica anual provável foi feita pelo modelo probabilístico de distribuição gama, caracterizado por Thom (1958) e recentemente utilizada por vários autores como Murta et al. (2005), Junqueria Junior et al. (2007) e Silva et al. (2007). Foram utilizados os seguintes níveis de probabilidade $5,10,15,20,25,30,35,40,45,50$, $55,60,65,70,75,80,85,90$ e $95 \%$. A função densidade de probabilidade foi obtida através da Equação 1:

$$
f(x)=\frac{1}{\beta^{\alpha} \Gamma(\alpha)} * x^{\alpha-1} e^{-\frac{\alpha}{\beta}}
$$

onde, $\alpha$ é parâmetro de forma (adimensional); $\beta$ o parâmetro de escala $(\mathrm{mm})$; e a base do logarítmo neperiano; x o total de precipitação $(\mathrm{mm})$ е г o símbolo da função gama, definida conforme Equação 2.

$$
\Gamma=\sqrt{2 \pi \alpha \alpha^{\alpha}} e^{\alpha}\left(1+\frac{1}{12 \alpha}+\frac{1}{288 \alpha^{2}}-\frac{139}{51840 \alpha^{3}}\right)
$$

Para a estimativa dos parâmetros foi utilizado o método dos momentos que consiste em equiparar a média $(\overline{\mathrm{X}})$ e a variância $\left(\mathrm{S}^{2}\right)$ da amostra à média e a variância da população gerando duas equações (Equações 3 e 4), como utilizado por Dallacort et al. (2011):

$$
\begin{aligned}
& \alpha=\frac{\bar{X}^{2}}{S^{2}} \\
& \beta=\frac{S^{2}}{\bar{X}}
\end{aligned}
$$

em que, $\overline{\mathrm{X}}$ é a precipitação média do período $(\mathrm{mm})$ e $\mathrm{S}^{2}$ o desvio padrão.

\section{RESULTADOS E DISCUSSÃO}

\subsection{Comportamento das médias pluviométricas anuais, mensais e decendiais}

De modo geral as médias mensais dos anos caracterizam duas fases distintas no comportamento da pluviosidade da região, uma chuvosa, de outubro a abril, e outra seca, de maio a setembro (Figura 2) como o esparado para região central do 


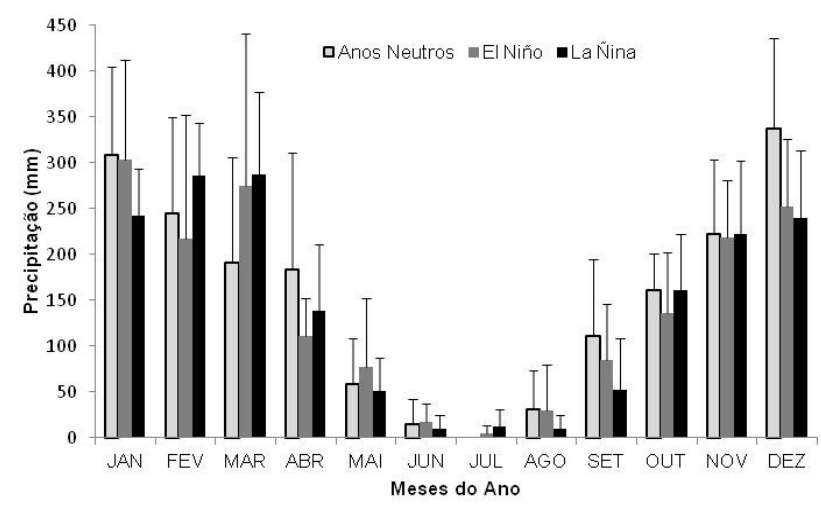

Figura 2: Médias pluviométricas mensais em anos com ocorrência de El Niño, La Niña e Anos neutros

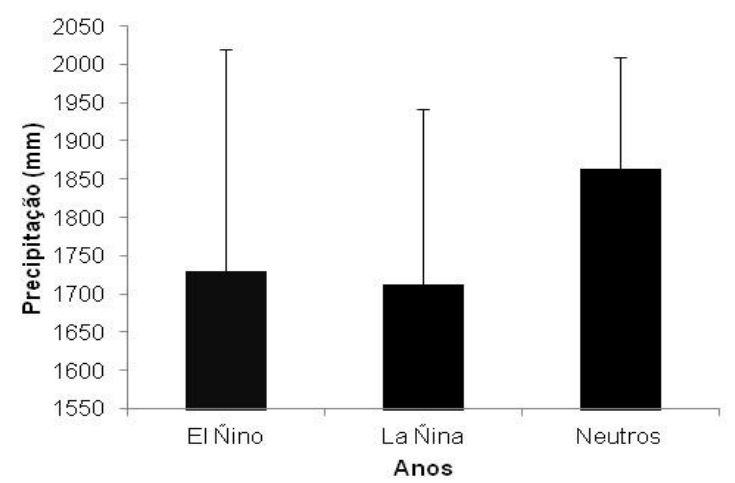

Figura 3: Médias pluviométricas anuais em anos com ocorrência de El Niño, La Niña e Anos neutros

Brasil. Corroborando com os resultados encontrados por Martins et al. (2010) em estudo realizado no município de Tangará da Serra - MT próximo a Diamantino.

A média dos anos neutros foi a maior encontrada entre os anos estudados (Figura 3), com um valor de $1.862,7 \mathrm{~mm}\left(\mathrm{~S}^{2}=\right.$ $146,32 \mathrm{~mm})$. O mês de dezembro apresentou a maior média, $337,33 \mathrm{~mm}\left(\mathrm{~S}^{2}=98,32 \mathrm{~mm}\right)$. O mês de julho não apresentou precipitação nestes anos diferente dos anos sobre efeito do ENOS. A média mensal encontrada foi $155,23 \mathrm{~mm}\left(\mathrm{~S}^{2}=132,53\right.$ $\mathrm{mm}$ ), dados próximos aos encontrados por Dallacort et al. (2011) para a cidade de Tangará da Serra - MT onde a média anual foi de $1.830,8 \mathrm{~mm}$.

Para os anos neutros, o decêndio 35 apresentou a maior média 139,92 mm ( $\left.\mathrm{S}^{2}=82,81 \mathrm{~mm}\right)$, e os decêndios 19, 20, 21 e 22 não apresentaram precipitação. A média dos decêndios foi de $51,79 \mathrm{~mm}\left(\mathrm{~S}^{2}=39,19 \mathrm{~mm}\right)$ (Figura 4).

Nos anos de La Niña a média foi $1.712,5 \mathrm{~mm}\left(\mathrm{~S}^{2}=228,75\right.$ $\mathrm{mm}), 8,06 \%$ a menos que os anos neutros e $0,97 \%$ abaixo do total precipitado em anos de El Niño, como o encontrado por Grimm et al. (2000) para todo o sul da América do Sul. Estes anos apresentaram o menor desvio encontrado entre os anos estudados, indicando uma menor variação da precipitação entre estes anos.
Junho foi o mês com a menor média para anos de La Niña, $9,94 \mathrm{~mm}\left(\mathrm{~S}^{2}=15,4 \mathrm{~mm}\right)$. O mês com a maior média foi março 286,60 mm ( $\left.\mathrm{S}^{2}=91,05 \mathrm{~mm}\right)$, este mês normalmente coincide com o período de colheita da safra de soja e de semeadura da segunda safra na região, o que pode gerar complicações e até perdas nestas operações.

Observa-se ainda um aumento na precipitação nos anos La Niña no final da estação chuvosa (fevereiro e março), assim deve-se adequar a semeadura das culturas para que os estádios de desenvolvimento mais exigentes em água coincida com este período diminuindo o risco de perdas por defict hídrico como preconiza Bergamaschi et al. (2004) para o milho, onde concluiu que a produtividade do milho, não importando a condição climática regional, é resultante das condições hídricas presentes no período crítico da cultura.

Para anos de El Niño, Ropelewski e Halpert (1987) concluíram que no Rio Grande do Sul e no Uruguai há uma tendência a ocorrer precipitação pluviométrica maior que a média histórica, já no presente estudo, os anos com influência do fenômeno apresentaram uma precipitação média 7,17\% abaixo da média de anos sem a influência do ENOS e superior a dos anos com influência de La Niña, apresentando média de $1.729,2 \mathrm{~mm}\left(\mathrm{~S}^{2}=290,52 \mathrm{~mm}\right)$. 


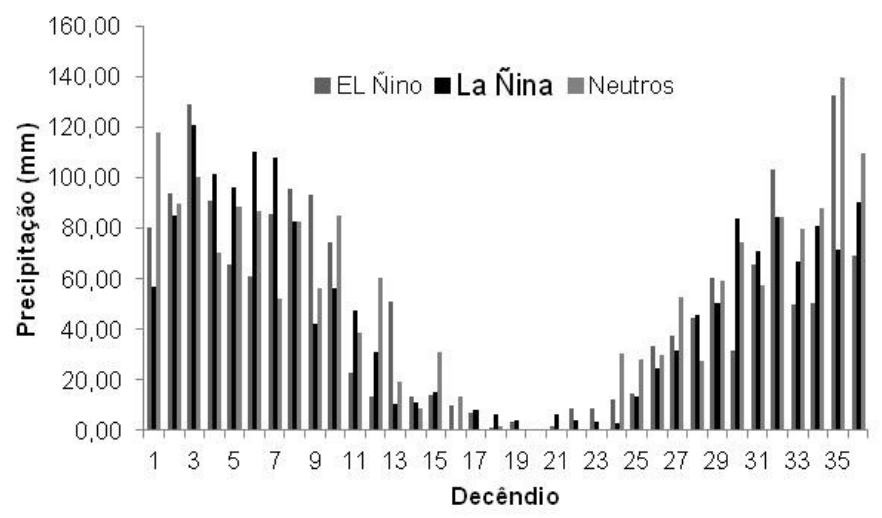

Figura 4: Médias pluviométricas anuais em anos com ocorrência de El Niño, La Niña e Anos neutros

Tabela 2: Valores de $\alpha$ e $\beta$, teste de Kolmogorov-Smirnov a 5\% e a média de desvio padrão

\begin{tabular}{ccccccc}
\hline & \multicolumn{5}{c}{ Kolmogorov-Smirnov (5\%) } \\
\cline { 2 - 7 } Ano & $\alpha$ & $\beta$ & D.M calc & D. M. tab. & $\bar{X}(\mathrm{~mm})$ & $\mathrm{S}^{2}(\mathrm{~mm})$ \\
\hline \multirow{2}{*}{ El Niño } & 35,43 & 48,81 & 0,19 & 0,49 & $1.729,2$ & 290,52 \\
La Niña & 56,05 & 30,55 & 0,13 & 0,41 & $1.712,5$ & 228,75 \\
& & & 0,25 & 0,52 & $1.862,7$ & 146,32 \\
\hline
\end{tabular}

Tabela 3: Precipitação provável para o município de Diamantino-MT

\begin{tabular}{cccccccc}
\hline \multirow{2}{*}{ Ano } & \multicolumn{7}{c}{ Precipitação Provável (mm) } \\
\cline { 2 - 8 } & $90 \%$ & $75 \%$ & $60 \%$ & $50 \%$ & $40 \%$ & $25 \%$ & $10 \%$ \\
\hline \multirow{2}{*}{ LN } & $1.426,67$ & $1.553,17$ & $1.645,23$ & $1.702,33$ & $1.760,73$ & $1.860,74$ & $2.011,41$ \\
EN & $1.368,89$ & $1.525,40$ & $1.640,80$ & $1.712,96$ & $1.787,20$ & $1.915,30$ & $2.110,40$ \\
N & $1.677,82$ & $1.762,03$ & $1.822,09$ & $1.858,87$ & $1.896,14$ & $1.959,19$ & $2.052,50$ \\
\hline
\end{tabular}

A maior média mensal em anos de El Niño ocorreu no mês de janeiro com 303,34 mm $\left(\mathrm{S}^{2}=109,32 \mathrm{~mm}\right)$. Por outro lado a menor média foi observada no mês de julho, 4,99 mm $\left(\mathrm{S}^{2}=9,30 \mathrm{~mm}\right)$, a média mensal foi de $144,1 \mathrm{~mm}\left(\mathrm{~S}^{2}=128,45\right.$ $\mathrm{mm}$ ) . O decêndio 35, assim como, nos anos neutros foi o que apresentou maior média nestes anos, 132,37 $\mathrm{mm}\left(\mathrm{S}^{2}=48,58\right.$ $\mathrm{mm})$, já decêndio 18 foi o que apresentou menor precipitação, $0,14 \mathrm{~mm}\left(\mathrm{~S}^{2}=0,38 \mathrm{~mm}\right)$. A média geral dos decêndios foi de $48,03 \mathrm{~mm}\left(\mathrm{~S}^{2}=\right.$ o $\left.38,42 \mathrm{~mm}\right)$.

\subsection{Probabilidade de precipitação}

O teste de Kolmogorov-Smirnov (Tabela 2), realizado em nível de $5 \%$ de probabilidade, indicou que os dados se adequavam ao modelo de distribuição gama (Figura 5).

Os anos neutros apresentaram os maiores valores de $\alpha \mathrm{e}$ menores valores e $\beta$ (Tabela 2 ), isto porque, em períodos com maior ocorrência de precipitação os valores de $\alpha$ (parâmetro de forma) tendem a serem maiores, pois a assimetria encontrada nos períodos mais secos é inversamente proporcional ao parâmetro como preconizaram Botelho e Morais (1999). Os anos com ocorrência de El Niño apresentaram valores intermediários de $\alpha$ e os maiores de $\beta$ e já os anos sob efeito de La Niña, os que apresentaram menor valor de $\alpha$ e o segundo maior de $\beta$.

Apesar das médias anuais se apresentarem na seguinte ordem decrescente: neutros, de El Niño e de La Niña, as precipitações prováveis (Tabela 3) não apresentaram em todos os níveis de precipitação esta ordem. Nos níveis compreendidos entre 90 e $60 \%$ os anos de El Niño apresentaram os menores valores, os anos com La Niña os valores foram intermediários e os anos neutros, o que pode ser explicado devido ao maior desvio padrão apresentado pelos anos sob a influência da fase quente do ENOS.

Desta maneira para o dimensionamento de um sistema de irrigação os anos de EL Niño exigem uma capacidade da maior de fornecimento de água, pois segundo Bernardo (1995) deve-se trabalhar com uma probabilidade de precipitação de no mínimo $75 \%$ para este fim. 


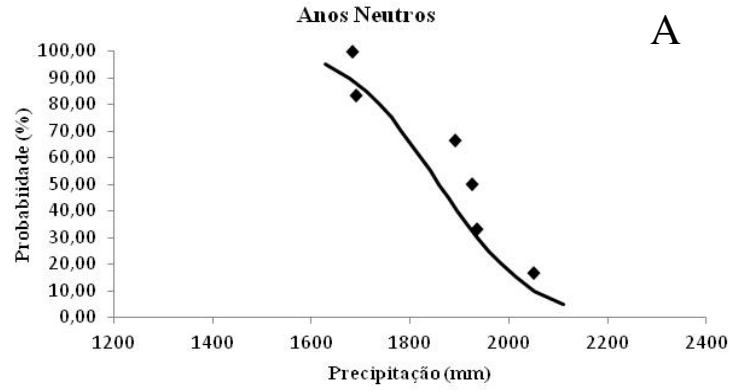

El Nino

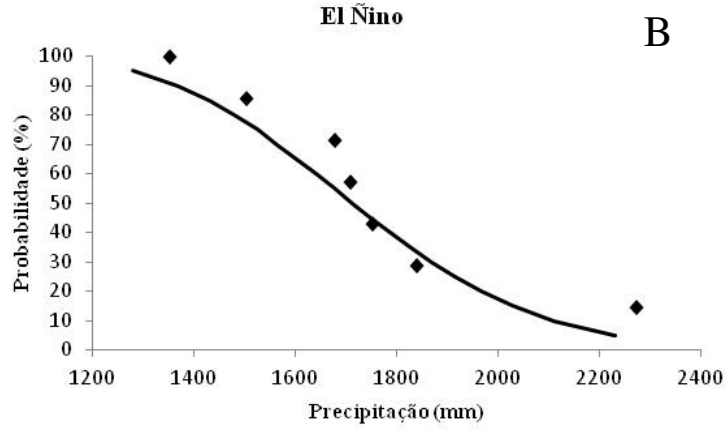

La Ñina

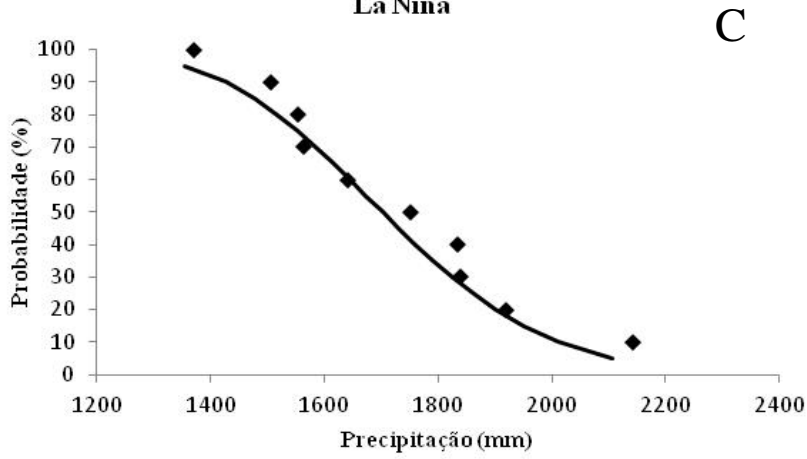

Figura 5: Adequação dos dados coletados em anos neutros (A), de El Niño (B) e com La Niña (C) à distribuição gama

Nos demais níveis de probabilidade a precipitação provável seguiu a média histórica, ou seja, os anos neutros apresentaram os maiores valores, os anos de El Niño com valores intermediários e com os menores valores os anos onde ocorreu a fase La Niña do ENOS.

\subsection{Quantificação de dias secos e chuvosos}

Os anos neutros foram o que apresentaram maior número médio de dias chuvosos (Figura 6), com média de 78,5 dias ( $\mathrm{S}^{2}=$ 5,09 dias) e, consequentemente, tiveram a menor média de dias secos (Figura 7), de 286,83 dias por ano ( $\mathrm{S}^{2}=4,75$ dias). Os anos neutros apresentaram o menor desvio padrão para dias secos e chuvosos, o que indica uma menor variação na distribuição das chuvas, mostrando uma maior variação da precipitação anual em anos sobre efeito do ENOS.

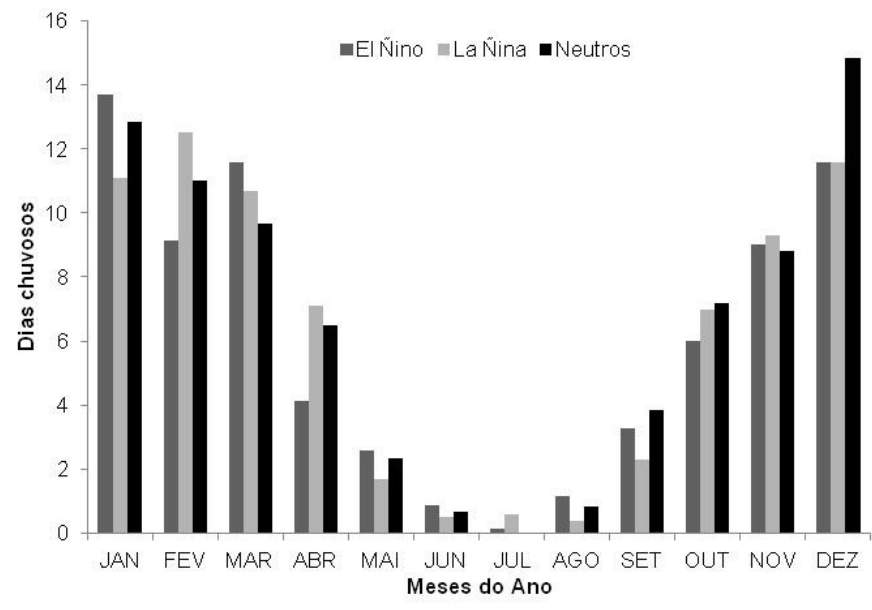

Figura 6: Distribuição mensal dos dias chuvosos

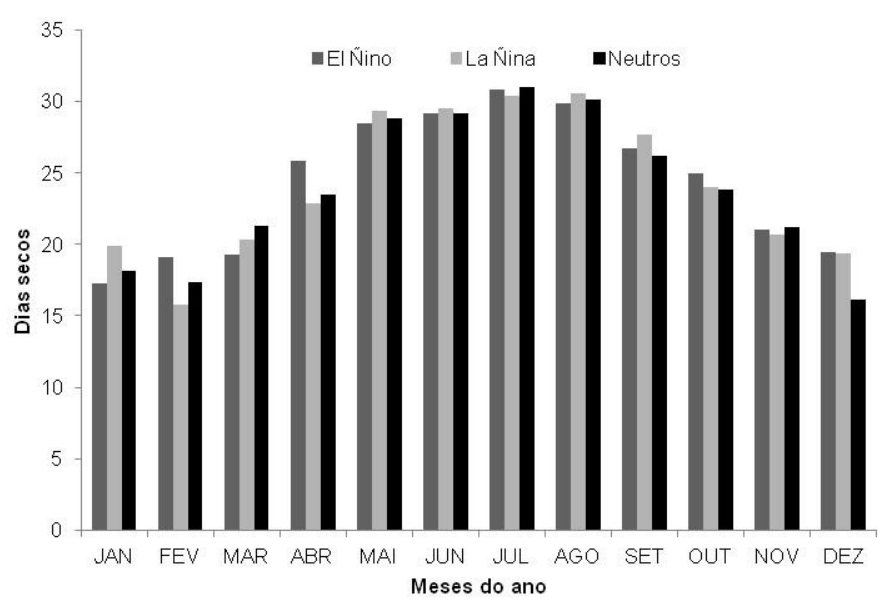

Figura 7: Distribuição mensal dos dias secos

Nos anos de La Niña, a média foi de 74,80 dias $\left(S^{2}=7,62\right.$ dias) e 290,50 dias por ano ( $\mathrm{S}^{2}=7,80$ dias), para dias chuvosos e secos respectivamente. Apesar dos anos com ocorrência desta fase apresentarem a menor média, foi observada a segundo maior média de dias chuvosos e a segunda menor média de dias secos.

Os anos com menores ocorrências de dias chuvosos e maiores de dias secos foram os que sofreram a influência da fase El Niño. Nestes anos houve uma média de 73,14 dias chuvosos por ano ( $\mathrm{S}^{2}=9,06$ dias $)$ e média de 292,00 dias secos $\left(\mathrm{S}^{2}=9,31\right)$, indicando um maior concentração da precipitação, uma vez que anos de La Niña apresentaram a uma altura pluviométrica 0,97\% menor que nos de El Niño e uma média de dias chuvosos de 74,80 .

Moreira et al. (2010) apresentaram valores próximos aos dos anos em estudo para o município de Nova Maringá - MT, vizinho à Diamantino, com média anual geral de 280 dias secos e 85 dias chuvosos. 


\subsection{Distribuição de frequência de precipitação diária}

As precipitações diárias de 5,1 a $10 \mathrm{~mm}$ (Tabela 4) apresentaram a maior média de ocorrência em todos os anos apresentando 20,83, 18,71 e 19,40 ano-1 para anos neutros, de El Niño e La Niña respectivamente, porém estas precipitações foram as que apresentaram a menor contribuição para a média anual (Tabela 5), totalizando $155,35 \mathrm{~mm}(8,86 \%)$ para anos neutros, $132,31 \mathrm{~mm}(8,12 \%)$ para anos com El Niño e 141,48 mm $(8,88 \%)$ para anos de La Niña.

Em anos neutros as precipitações de menor ocorrência foram maiores do que $50 \mathrm{~mm}$ (Tabela 4) com uma média de 5,67 ocorrências no ano. No entanto, este intervalo de precipitação representou $22,46 \%$ da média da precipitação anual, sendo as precipitações com o maior volume precipitado, uma média de 393,92 mm (Tabela 5).

Em anos de El Niño, as precipitações de menor média de ocorrência foi 40,1 a $50 \mathrm{~mm}$ com 4 ocorrências, já as chuvas com mais de $50 \mathrm{~mm}$ apresentaram uma ocorrência de $5,71 \mathrm{e}$ apresentaram maior média precipitada $419,14 \mathrm{~mm}$, média $6,4 \%$ maior que a de anos neutros nesta intensidade e $47 \%$ maior que em anos de La Niña, onde esta intensidade precipitou em média $284,03 \mathrm{~mm}$, indicando portanto uma maior intensidade da precipitação em anos sob efeito da fase El Niño do ENOS do que em anos neutros e com a influência da fase La Niña.

Para os anos de La Niña, a intensidade com menor ocorrência foi a de 40,1 a $50 \mathrm{~mm}$ com 3,80 ocorrências.
A intensidade de 20,1 a $30 \mathrm{~mm}$ foi onde houve maior total precipitado $342,47 \mathrm{~mm}$, representando $21,49 \%$ do total precipitado. Nos anos neutros o total precipitado nessa intensidade foi maior $347,32 \mathrm{~mm}$, porém representou apenas $19,80 \%$ da média destes anos. Isto indica menor intensidade da precipitação em anos sob a fase La Niña do ENOS, demonstrando maior distribuição das chuvas.

Nos anos neutros as chuvas maiores que $50 \mathrm{~mm}$ se concentraram nos meses compreendidos entre novembro e fevereiro (Tabela 6), com o mês de dezembro apresentando maior ocorrência. Isso pode ser explicado pelo fato de dezembro ser o mês de maior precipitação nestes anos.

Observa-se que as chuvas de 40,1 a $50 \mathrm{~mm}$ nos anos neutros, assim como as maiores que $50 \mathrm{~mm}$, ocorreram mais no período de novembro a fevereiro, mostrando uma tendência de intensificação das chuvas nestes meses, que também se confirma nos anos de El Niño e La Niña.

O maior número de ocorrência de chuvas maiores ou iguais a $50 \mathrm{~mm}$ em anos de El Niño (Tabela 7) se dá em janeiro, mês mais chuvoso para estes anos, e para os anos com La Niña (Tabela 8 ) em março que por sua vez também é o mês mais chuvoso para estes anos.

Os anos de El Niño apresentaram uma média de 4,14 ocorrências de chuvas de 5,1 a $10 \mathrm{~mm}$ no mês de janeiro, valor superior ao apresentado por anos neutros e de La Niña, 3,33 e 2,80 ocorrências, respectivamente. Esse comportamento ainda pode ser observado no mês de março, onde a média de

Tabela 4: Média de ocorrência de dias com chuvas de diferentes intervalos de precipitação.

\begin{tabular}{cccc}
\hline \multirow{2}{*}{ Intensidades de precipitação } & \multicolumn{3}{c}{ Anos } \\
\cline { 2 - 4 } & Neutros (dias) & El Niño (dias) & La Niña (dias) \\
\hline 5,1 a $10 \mathrm{~mm}$ & 20,83 & 18,71 & 19,40 \\
10,1 a $15 \mathrm{~mm}$ & 15,33 & 15,71 & 14,40 \\
15,1 a $20 \mathrm{~mm}$ & 9,33 & 10,29 & 10,70 \\
20,1 a $30 \mathrm{~mm}$ & 14,17 & 12,14 & 13,70 \\
30,1 a $40 \mathrm{~mm}$ & 7,33 & 6,57 & 8,40 \\
40,1 a $50 \mathrm{~mm}$ & 5,83 & 4,00 & 3,80 \\
>50,1 $\mathrm{mm}$ & 5,67 & 5,71 & 4,40 \\
\hline
\end{tabular}

Tabela 5: Média anual de precipitação em diferentes intervalos de precipitação

\begin{tabular}{cccc}
\hline \multirow{2}{*}{ Intensidade de precipitação } & \multicolumn{3}{c}{ Anos } \\
\cline { 2 - 4 } & Neutros (mm) & El Niño (mm) & La Niña (mm) \\
\hline 5,1 a $10,1 \mathrm{~mm}$ & 155,35 & 132,31 & 141,48 \\
10,1 a $15 \mathrm{~mm}$ & 187,68 & 190,84 & 179,75 \\
15,1 a $20 \mathrm{~mm}$ & 163,23 & 181,54 & 186,02 \\
20,1 a $30 \mathrm{~mm}$ & 347,32 & 297,06 & 342,47 \\
30,1 a $40 \mathrm{~mm}$ & 248,03 & 229,64 & 289,10 \\
40,1 a $50 \mathrm{~mm}$ & 258,65 & 178,70 & 170,54 \\
$>50,1 \mathrm{~mm}$ & 393,92 & 419,14 & 284,03 \\
\hline
\end{tabular}


Tabela 6: Frequência de precipitação diária mensal em anos neutros

\begin{tabular}{|c|c|c|c|c|c|c|c|}
\hline \multirow[b]{2}{*}{$\begin{array}{l}\text { Meses } \\
\text { do ano }\end{array}$} & \multicolumn{7}{|c|}{ Intensidade de precipitação $\left(\mathrm{mm} .24 \mathrm{~h}^{-1}\right)$} \\
\hline & $5,1-10,1$ & $10,1-15$ & $15,1-20$ & $20,1-30$ & $30,1-40$ & $40,1-50$ & $>50,1$ \\
\hline JAN & 3,33 & 3,00 & 1,33 & 1,33 & 0,67 & 1,50 & 0,67 \\
\hline FEV & 3,17 & 1,50 & 1,50 & 1,50 & 1,17 & 0,50 & 0,67 \\
\hline MAR & 2,50 & 2,17 & 1,50 & 1,50 & 0,83 & 0,50 & 0,17 \\
\hline $\mathrm{ABR}$ & 1,83 & 1,17 & 0,17 & 0,17 & 0,67 & 0,33 & 1,17 \\
\hline MAI & 0,67 & 0,50 & 0,17 & 0,17 & 0,17 & 0,00 & 0,33 \\
\hline JUN & 0,33 & 0,00 & 0,00 & 0,00 & 0,00 & 0,17 & 0,00 \\
\hline JUL & 0,00 & 0,00 & 0,00 & 0,00 & 0,00 & 0,00 & 0,00 \\
\hline AGO & 0,00 & 0,33 & 0,00 & 0,00 & 0,00 & 0,33 & 0,17 \\
\hline SET & 0,83 & 1,00 & 0,83 & 0,83 & 0,50 & 0,00 & 0,67 \\
\hline OUT & 1,83 & 1,17 & 0,83 & 0,83 & 0,83 & 1,17 & 0,00 \\
\hline NOV & 1,83 & 1,33 & 1,50 & 1,50 & 0,67 & 0,50 & 0,83 \\
\hline DEZ & 4,50 & 3,17 & 1,50 & 1,50 & 1,83 & 0,83 & 1,00 \\
\hline
\end{tabular}

Tabela 7: Frequência de precipitação diária mensal em anos neutros

\begin{tabular}{|c|c|c|c|c|c|c|c|}
\hline \multirow{2}{*}{$\begin{array}{l}\text { Meses } \\
\text { do ano }\end{array}$} & \multicolumn{7}{|c|}{ Intensidade de precipitação $\left(\mathrm{mm} .24 \mathrm{~h}^{-1}\right)$} \\
\hline & $5,1-10$ & $10,1-15$ & $15,1-20$ & $20,1-30$ & $30,1-40$ & $40,1-50$ & $>50,1$ \\
\hline JAN & 4,14 & 2,57 & 2,71 & 1,86 & 0,71 & 0,71 & 1,00 \\
\hline FEV & 2,14 & 2,71 & 0,86 & 1,43 & 0,71 & 0,71 & 0,57 \\
\hline MAR & 3,43 & 2,00 & 1,57 & 1,71 & 0,86 & 0,86 & 1,14 \\
\hline $\mathrm{ABR}$ & 1,00 & 0,29 & 0,71 & 1,43 & 0,29 & 0,00 & 0,43 \\
\hline MAI & 0,43 & 0,29 & 0,29 & 0,43 & 0,57 & 0,29 & 0,29 \\
\hline JUN & 0,14 & 0,29 & 0,14 & 0,00 & 0,29 & 0,00 & 0,00 \\
\hline JUL & 0,00 & 0,00 & 0,00 & 0,14 & 0,00 & 0,00 & 0,00 \\
\hline AGO & 0,29 & 0,00 & 0,43 & 0,14 & 0,14 & 0,00 & 0,14 \\
\hline SET & 0,57 & 0,71 & 0,14 & 1,00 & 0,29 & 0,14 & 0,43 \\
\hline OUT & 2,00 & 1,29 & 0,57 & 0,57 & 1,00 & 0,43 & 0,14 \\
\hline NOV & 1,86 & 2,71 & 1,14 & 1,29 & 0,71 & 0,57 & 0,71 \\
\hline DEZ & 2,71 & 2,86 & 1,71 & 2,14 & 1,00 & 0,29 & 0,86 \\
\hline
\end{tabular}

Tabela 8: Frequência de precipitação diária mensal em anos de La Niña

\begin{tabular}{cccccccc}
\hline Meses & \multicolumn{7}{c}{ Intensidade de precipitação $\left(\mathrm{mm} .24 \mathrm{~h}^{-1}\right)$} \\
\cline { 2 - 8 } do ano & $5,1-10,1$ & $10,1-15$ & $15,1-20$ & $20,1-30$ & $30,1-40$ & $40,1-50$ & $>50,1$ \\
\hline JAN & 2,80 & 2,20 & 1,7 & 1,7 & 0,9 & 0,5 & 0,4 \\
FEV & 2,60 & 2,50 & 2,0 & 2,0 & 1,7 & 0,6 & 0,7 \\
MAR & 1,90 & 1,90 & 1,6 & 1,6 & 1,6 & 0,7 & 1 \\
ABR & 3,00 & 1,10 & 0,7 & 0,7 & 0,5 & 0,4 & 0,3 \\
MAI & 0,60 & 0,10 & 0 & 0 & 0,3 & 0,1 & 0,2 \\
JUN & 0,20 & 0,10 & 0 & 0 & 0,1 & 0 & 0 \\
JUL & 0,10 & 0,10 & 0,1 & 0,1 & 0 & 0 & 0 \\
AGO & 0,10 & 0,00 & 0,1 & 0,1 & 0,1 & 0 & 0 \\
SET & 0,90 & 0,20 & 0,2 & 0,2 & 0,1 & 0,1 & 0,2 \\
OUT & 1,40 & 1,90 & 1,2 & 1,2 & 0,9 & 0,4 & 0,5 \\
NOV & 2,60 & 1,40 & 1 & 1 & 1,4 & 0,5 & 0,5 \\
DEZ & 3,20 & 2,90 & 2,1 & 2,1 & 0,8 & 0,5 & 0,6 \\
\hline
\end{tabular}


ocorrências de precipitações neste intervalo para anos de El Niño foi 3,43, para anos neutros foi de 2,50 ocorrências e 1,90 para anos de La Niña.

\section{CONCLUSÕES}

1. A fase La Niña do ENOS é que mais altera a distribuição temporal das chuvas em relação aos anos neutros, apresentando os maiores valores precipitados do quarto decêndio do ano ao sétimo.

2. Os anos de El Niño apresentaram as maiores precipitações diárias no período compreendido entre os meses de janeiro a março.

3. Os anos neutros apresentaram uma precipitação provável anual ano nível de $75 \%$ de $1.762,03 \mathrm{~mm}$, os anos de La Niña $1.553,17 \mathrm{~mm}$ e os anos de El Niño $1.525,40 \mathrm{~mm}$.

\section{AGRADECIMENTOS}

Agradeço ao CNPQ e FAPEMAT pelo apoio financeiro as pesquisas e as bolsas concedidas.

\section{REFERÊNCIAS BIBLIOGRÁFICAS}

ALVES, M. B.; SOUZA, E. B.; REPELLI, C. A.; VITORINO, M. I.; FERREIRA, N. S. Episódios de La Niña na bacia do oceano pacífico e equatorial e a distribuição sazonal e intrasazonal das chuvas no setor norte do nordeste brasileiro. Revista Brasileira de Meteorologia, v. 12, n. 1, p.63-76, 1997.

BERGAMASCHI, H.; DALMAGO, G. A.; BERGONCI,J. I.; BIANCHI, C. A. M.; MÜLLER, A. G.; COMIRAN, F.; HECKLER, B. M. M. Distribuição hídrica no período crítico do milho e produção de grãos. Pesquisa Agropecuária Brasileira, v. 39, n.9, p.831-839, 2004.

BERLATO, M. A.; FARENZENA, H.; FONTANA, D.C. Associação entre El Niño Oscilação Sul e a produtividade do milho no Estado do Rio Grande do Sul. Pesquisa Agropecuária Brasileira, v.40, n.5, p.423-432, 2005.

BERNARDO, S. Manual de irrigação. 6.ed. Viçosa: Imprensa Universitária, 1995. 657p.

BOTELHO, V. A.; MORAIS, A. R.. Estimativas dos parâmetros de distribuição Gama de dados pluviométricos do município de Lavras, Estado de Minas Gerais. Revista Ciência e Agrotecnologia, v.23, n. 3, p. 697-706, 1999.

CARMONA, L. C.; BERLATO, M. A. El Niño e La Niña e o rendimento do arroz irrigado no Estado do Rio Grande do Sul. Revista Brasileira de Agrometeorologia, v. 10, n. 1, p. 147-152, 2002.

CUNHA, G. R. El Niño-Oscilação Sul e perspectivas climáticas aplicadas no manejo de culturas no Sul do
Brasil. Revista Brasileira de Agrometeorologia, v. 7, n. 2, p. 277-284, 1999.

DALLACORT, R.; MARTINS, J. A.; INOUE, M. H.; FREITAS, P. L.; COLLETI, A. J. Distribuição das chuvas no município de Tangará da Serra, médio norte do Estado de Mato Grosso, Brasil. Acta Scientiarum Agronomy, v. 33, n. 2, p. 193-200, 2011.

DUBREUIL, V.; BARIOU, R.; PASSOS, M.; FERRAND, R.; NÉDÉLEC, V. Evolução da fronteira agrícola no centrooeste de mato grosso: municípios de Tangará da Serra, Campo Novo do Parecis e Diamantino. Cadernos de Ciência e Tecnologia, v. 22, n. 2, p. 463-478, 2005.

FARIA, R. T.; CHIBANA, E. Y.; CARAMORI, P. H. Programa computacional para organização e análise de dados meteorológicos. Engenharia Agrícola, v.23, n.2, p. 372 $387,2003$.

GRIMM, A. M.; BARROS, V. R.; DOYLE M. E. Climate Variability in Southern South America Associated with El Niño and La Niña Events. Journal of Climate, vol. 13, n. 1, p. 35-57, 2000.

JUNQUEIRA JÚNIOR, J. A.; Gomes, N. M.; Mello, C.; R.; Silva, A. M. Precipitação provável para a região de Madre de Deus, Alto Rio Grande: modelos de probabilidades e valores característicos. Ciência Agrotécnica, v. 31, n. 3, p. 842-850, 2007.

MARTINS, J. A.; DALLACORT, R.; INOUE, M. H.; SANTI, A.; KOLlinG, E. M.; COLLETI, A. J. Probabilidade de precipitação para a microrregião de Tangará da Serra, Estado do Mato Grosso. Pesquisa Agropecuária Tropical, v. 40, n.3, p. 291-296, 2010.

MOREIRA P. S. P.; DALLACORT R.; MAGALHÃES R. A.; INOUE M. H.; STIELER M. C.; SILVA D. J.; MARTINS J. A. Distribuição e probabilidade de ocorrência de chuvas no município de nova Maringá-MT. Revista de Ciências Agro-Ambientais, v. 8, n. 1, p. 9- 20, 2010.

MURTA, R. M.; TEODORO, S. M.; BONOMO, P.; CHAVES, M. A. Precipitação pluvial mensal em níveis de probabilidade pela distribuição gama para duas localidades do sudoeste da Bahia. Ciência agrotécnica, v. 29, n. 5, p. 988-994, 2005.

PEREIRA, A. R.; ANGELOCCI, L. R.; SENTELHAS, P. C. Agrometeorologia: Fundamentos e Aplicações Práticas. Guaíba: Agropecuária, 478 p., 2002.

PODESTÁ, G.P.; MESSINA, C. D.; GRONDONA, M. O.; MAGRIN, G. O. Association between grain crop yields in central-eastern Argentina and El Niño-south oscillation. Journal of Applied Meteorology, v. 38, n. 10, p. 1488-1498, 1999.

ROPELEWSKI, C. F.; HALPERT, M.S. Global and regional scale precipitaton patterns associated with the El Niño/ 
Southern Oscilation. Monthly Weather Review, v. 115, n. 8, p. 1606-1626, 1987.

SANS, L. M. A.; ASSAD, D.; GUIMARÃES, D. P.; AVELAR, G. Zoneamento de riscos climáticos para a cultura do milho na região centro-oeste do Brasil e para o estado de Minas Gerais. Revista Brasileira de Agrometeorologia, v. 9, n. 3, p. 527-539, 2001.

SILVA, J. C.; HELDWEIN, A. B.; MARTINS, F. B.; TRENTIN, G.; GRIMM, E. L. Análise de distribuição de chuva para Santa Maria, RS. Revista Brasileira de Engenharia Agrícola Ambiental, v.11, n.1, p.67-72, 2007.
SOUSA, S. A. V. Programa computacional para simulação da ocorrência de veranicos e queda de rendimento. Pesquisa Agropecuária Brasileira, v.33, n. 12, p. 1992-1956, 1998.

THOM, H. C. S. A note on the gama distribution. Monthly Weather Review, v. 86, n. 4, p. 117-122, 1958. 